\title{
Article \\ Contradictory Conservation: The Role of Leadership in Shaping Energy Efficiency Culture in Urban Residential Cooperative Buildings
}

\author{
Elizabeth Hewitt
}

check for

updates

Citation: Hewitt, E. Contradictory Conservation: The Role of Leadership in Shaping Energy Efficiency Culture in Urban Residential Cooperative Buildings. Energies 2021, 14, 648. https://doi.org/10.3390/en14030648

Academic Editor: Marta Lopes Received: 25 December 2020

Accepted: 22 January 2021

Published: 27 January 202

Publisher's Note: MDPI stays neutral with regard to jurisdictional claims in published maps and institutional affiliations.

Copyright: (C) 2021 by the author. Licensee MDPI, Basel, Switzerland. This article is an open access article distributed under the terms and conditions of the Creative Commons Attribution (CC BY) license (https:// creativecommons.org/licenses/by/ $4.0 /)$.
Department of Technology and Society, College of Engineering and Applied Sciences (CEAS), Stony Brook University, Stony Brook, NY 11794, USA; elizabeth.hewitt@stonybrook.edu; Tel.: +1-631-632-3241

\begin{abstract}
In addition to formalized leadership roles within organizations, leadership can also influence members through informal channels. This work argues that multifamily residential buildings can be viewed as organizations and, as such, explores the influence that informal leaders can wield in shaping culture around the motivation for conserving energy. This work draws on qualitative fieldwork conducted in a Brooklyn cooperative building. Findings indicate that the study building benefitted from the leadership of a long-standing board member, which contributed to the implementation of a number of energy efficiency initiatives. Interestingly, this leadership also led to a culture of cost efficiency over environmental concern as the motivating force behind these initiatives. This narrative was well disseminated, with most residents reporting that the building does not have a culture of conservation, despite a strong energy efficiency leaning. Thus, this work posits that leadership can greatly shape perception and culture around energy but can also be leveraged to craft a more environmentally-motivated conservation culture. It also argues that leadership can be complementary to decentralized organizational structures, and that creative mechanisms in residential buildings can capitalize on both, allowing members at all levels of the organization more influence in shaping the building's culture.
\end{abstract}

Keywords: residential buildings; energy efficiency; leadership; behavior; organizational culture

\section{Introduction}

Organizations can be viewed as an important scale of analysis for understanding and ultimately reducing energy use [1,2]. Leadership in traditional organizations is typically formalized through roles such as manager or supervisor. These structured positions are important; indeed, strong leaders play a key part in shaping outcomes and influencing behavior in organizations [3-7]. However, leadership need not always be through formal pathways; it can also be informal and ad-hoc, influencing outcomes through non-traditional organizational mechanisms and non-traditional organizations. For example, this work argues that residential multifamily buildings in urban areas can function as organizations and have similar characteristics and operational structures [2]. This lens taps into the social component of residential buildings, and acknowledges a possible network of influence among various actors within the building [8-11]. To that end, some buildings may have residents that embrace an informal role as a leader within the building, and this can have significant influence on culture, perception, and social norms among residents. Adhoc leaders in buildings may make use of non-traditional mechanisms of influence. In particular, social norms and culture in the building may be shaped by informal conversation, interactions, and narratives.

This work seeks to better understand the role that leadership can play in shaping organizational culture surrounding energy conservation in buildings. It draws on qualitative fieldwork conducted in a small New York City cooperative building in early 2015, including a survey of residents and in-depth interviews with cooperative board members. 
In particular, this research attempts to understand the culture and perception surrounding energy and environmental initiatives in the building, the role leadership has had in shaping this culture, and, finally, the effectiveness of the mechanisms used for influencing perception. It also seeks to understand the role of the building's organizational structure in supporting or hindering the ability of a leader to influence a culture of energy conservation in the building.

This research contributes to existing work by offering new contributions to organizational research by framing the building as the organization, and by exploring energy outcomes through this lens. Some researchers $[2,9,12]$ are bringing an organizational framework to the study of energy in buildings, but this approach is still new, and more work is needed.

\subsection{Leadership and Organizational Culture}

Influential residents in multifamily buildings who take on roles as "peer leaders" may exhibit characteristics that help engage moral and ethical aspects of decision making, key characteristics of strong leaders in the pro-environmental sphere [13,14]. Leadership plays an important role in shifting behavior in groups and organizations [3,7]. Importantly, positions of informal leadership may create compelling narratives of environmental responsibility around energy conservation.

In public policy research it is known that narratives are a widely used tool to bolster legitimacy on issues and set the agenda for policymaking [15]. This lens can be extended to organizations. Broadly, narratives make use of language to convey facts and shape understanding, opinion and perception $[15,16]$. In organizations specifically, which is the lens used here, organizational leaders make use of language and narratives to shape the organizational view of problems and projects, and these narratives impact project outcomes and the ways in which members tackle issues [17]. These authors note the importance of language in shaping reality, especially when situations in organizations are uncertain or ambiguous. Narratives used by leaders tend to be more influential and successful when the individual has organizational legitimacy [18]. Leaders will likely be perceived as more legitimate "messengers" than non-leaders.

Buildings offer an interesting site to convey message and meaning around energy efficiency. When the organizational unit is a residential building, the types of interaction between organizational members are quite different than they would be in a traditional organization (e.g., an office). Individual members (residents) interact in informal, casual and more intimate ways. Culture and social norms are conveyed in hallways, elevators, lobbies, shared recreational space, and roof gardens. These settings differ from the typical office space, and the interactions differ from the typical boss-subordinate role. In particular, they offer opportunities for less formal, somewhat incomplete, and "unrehearsed" culture sharing and narratives. Such incomplete narratives could be a good way to assess the diffusion of new and unestablished practices and programs [19].

\subsection{The Importance of Building Type}

The type of building is likely to play a role in the effectiveness of an informal leader's influence. For example, influence is likely to be more effective in buildings that are owneroccupied, and in particular those that rely on a collective ownership structure, such as a cooperative, where all residents are responsible for capital improvements and building maintenance over time. In addition, these owner-occupied buildings have more interaction among residents and more shared decision-making and governance.

Owner-occupied urban housing units in multifamily buildings have historically been (and continue to be) particularly popular in New York City [20-22]. Condominiums and cooperatives share many characteristics of governance and legal structure, but cooperatives are a unique and distinct form of ownership, and pre-date condominiums in the United States [21-23]. New York City is the only metropolitan area in the U.S. where cooperatives exceed condominium units [22]. As Low [20] reports, over $80 \%$ of all U.S. co-ops are 
located in New York City. Cooperative buildings are legally structured as corporations and governed by a board comprised of residents and owners, with governance conferred based on shares owned [21-23]. Although condominiums also have a board governance system to manage building finances and common area repairs and maintenance, cooperatives typically have more legal power and responsibility because they collectively own the entire building, not just common areas [21-23].

Cooperatives can also be distinguished from condominiums by their buyer selection and acceptance process, in which the board serves a strong role as "gatekeeper." In cooperative buildings, all sales and purchases must undergo approval by the board and all potential buyers and incoming residents must undergo thorough financial, professional, and personal checks. Although legally cooperatives cannot discriminate against qualified buyers based on any non-financial characteristics, Low et al. [21] explain that cooperative boards need not ever provide any explanation for reasons for rejection of a potential buyer. Thus, cooperative buildings are much more tightly controlled and "exclusive" residential structures, and there is a good amount of self-selection that occurs with the decision to locate in a cooperative.

\subsection{Social Norms for Energy Efficiency}

Individuals rarely make decisions to engage in pro-environmental behavior for purely altruistic reasons. Instead, influencing factors include cost savings, physical or psychological comfort, habits, and/or social norms [24,25]. Parsing these motivations is a complex undertaking. Some measure of social norm is included by various researchers in theoretical frameworks for decision-making and pro-environmental behavior [26-30]. Social norms can be defined as an influence of one's peer group on behavior and action, and such norms can be assessed in a variety of ways, including measures of perceived peer expectations, perceptions of socially acceptable behaviors, and responses to feedback mechanisms about behavior.

Energy efficiency researchers [3,31,32] have reported success with conservation measures that induce such norms by creating mechanisms for households to compare their behavior to neighbors, and in recycling research outside of the U.S. some success has been reported with residential feedback measures [33]. Evidence from the energy industry indicates that inclusion of a notification in monthly energy bills comparing a resident's electricity consumption to that of his/her neighbors was effective in lowering energy consumption $3-5 \%[31,32]$. Importantly, competition has been found to induce more sustainable actions even in individuals who are less concerned with environmental problems [34].

Given the knowledge about the success of norms in influencing behavior, leaders can leverage norms to shape outcomes and culture surrounding energy efficiency.

\section{Materials and Methods}

\subsection{Analytical Approach}

The overarching methodology for this work is a qualitative case study. The goal of this analysis is to provide a more in-depth understanding of the types of energy efficiency initiatives the building has undertaken, the motivations for undertaking them, and opinions and culture surrounding them. In addition, an aim of this work is to provide context about the organizational structure of the building. In particular, this work explores the role of key leader(s) in the building, and the impact these individuals may have had on culture and perceptions among others. This will be explored using a combination of survey and interview data.

Because only a single building is analyzed as a case study, results are triangulated between a survey and in-depth interviews, with the goal of connecting similar themes and looking for contextual clues and nuance in responses. Although surveys are typically quantitative in nature, the small sample size and single-building research site presented here lend themselves to purely descriptive and qualitative results; no statistical analysis is feasible in this work. To that end, triangulation is very important, as it helps to con- 
firm findings. The interviews were coded for important language and themes and then connected to relevant theory and other empirical evidence in the field.

Additionally, given the single case and site studied here, findings should not be generalized to all cooperative buildings, or even owner-occupied units more broadly $[35,36]$. More data and research are needed before replicability can be determined. However, case study methodology is an important part of qualitative research that can offer valuable insights to the unique and situational context of the case at hand [35-37]. It was the opinion of the author that this particular case and building (which was part of a larger study) was unique and merited closer study.

\subsection{Site and Site Selection}

The site for this research is a small cooperative building located in the Prospect Heights neighborhood in the borough of Brooklyn in New York City. The property was built in 1909 and is a pre-war brick-exterior multi-family walk-up building with 16 residential units and 4 floors. The building contains a mix of two- and three-bedroom units. The property is approximately $13,000 \mathrm{SF}$ and also contains a shared basement facility with laundry and storage, and a shared backyard with outdoor amenities such as a grill, seating, and children's toys. The building does not have a centralized ventilation system for heating and cooling; heat is provided by natural gas (after a switch from oil approximately 6 years ago), and residents rely on window air conditioners during summer months. The property converted from a rental to a cooperative building in 1988. To protect resident privacy, the address of the building and some identifying details have been anonymized.

The selection of this single-case building was derived from snowball sampling in order to derive a sample of 10 buildings for a larger research study. Of the ten buildings, this was the only cooperative building. The ten buildings were selected in part due to site access and the willingness of the building community to participate in this research. Given the difficulty with gaining access to private residential properties in New York City, and the role of gatekeeper played by the building manager and/or concierge, availability of access was a key driver in the overall sample selection and the use of this building as a site for research [36].

\subsection{Methodology}

A survey was conducted building-wide during February 2015 via an online website link that was circulated to residents by a board member on their online Google message board portal (so as to ensure that all resident emails remained private during this data collection process). The survey consisted of three parts and a total of 21 questions; it took approximately 5-10 min to complete. The survey remained open for a three-week period. All adult residents of the cooperative building ( 24 individuals) were invited to take the survey (even those from the same household), and 12 responses were received (50\%). Residents were offered the chance to enter a drawing for one \$50 Amazon gift card for completing the survey in full by entering their email address on the last page of the survey (which was not connected to individual survey responses).

The survey was developed in two key ways: (1) First, overarching research questions that were identified for the larger research study of which this was a part pointed to the need to further analyze owner-occupied properties in general and cooperative buildings in particular, with leadership and organizational structure providing key insights. This led to careful crafting of survey questions around these themes. (2) The question wording and development was informed by well-cited social science and survey research, both methodological and empirical, including [35,36,38], and [30,39]. For example, the section of the survey that assessed residents' level of concern for the environment focused on biophilic values [40]. This work is highly cited, and was informed by numerous prior studies, including $[30,41,42]$. Additionally, prior published work by the author made use of similar questions and scales [24]. Once the survey was developed, it was reviewed by 
subject-matter experts, and then piloted among a small group of test respondents to assess question clarity, coherence and flow.

The three parts of the survey covered three different sets of questions. Part A consisted of questions about the occupant's perception of and opinion about the building, their neighbors, and the cooperative board. Part B consisted of questions about the respondent's energy and environmental opinions in the building and their household. Part $\mathrm{C}$ asked respondents for information about their demographics. The survey instrument is available as Appendix A.

The survey questions were validated in three ways: (1) First, they were assessed for alignment with similar empirically tested research that intended to measure similar constructs (see those mentioned above); although questions were modified to fit the unique context of this single case [35] questions were determined to be well aligned with existing precedents. (2) Questions were vetted by subject-matter experts prior to distribution of the survey; and, (3) multiple questions were included in the survey that were intended to test the same measures, which aligns with guidance from [38].

Although twelve responses is a low number and does not allow for robust statistical analysis, given the size of the building this $50 \%$ response rate represents a good portion of the residents, and still provides valuable qualitative insight in to their interactions with one another and the cooperative board.

Social desirability bias can be problematic with any survey data; to ameliorate this issue, a few strategies of survey design were employed. First, questions asked about specific behaviors in clear and simple wording, and in many cases used simple Likert scales, which typically garners more accurate responses from participants than more vague wording (e.g., "have you ever ... "). Second, individuals are known to be more honest in responses if they can take surveys in private, rather than face-to-face with a survey administrator; thus, surveys were administered online, not in-person, giving respondents more freedom to answer honestly [38].

In addition to the building-wide survey, three in-depth (1 to $2 \mathrm{~h}$ ) open-ended interviews were conducted [43]. Two were conducted with the same resident (the first about her opinions and experiences in the building more broadly, and the second follow-up interview concentrating on her time as prior years' board president and vice-president), referred to here as Resident, and one was conducted with the long-standing (25+ year) board treasurer who was one of the original sponsors of the cooperative conversion, referred to here as Treasurer. No other residents volunteered to be interviewed.

\subsection{Participants}

The building houses 16 apartments, of which two remained low-income rent-controlled rentals after the cooperative conversion in the 1980s. In addition, residents elected to retain one basement unit as a market rate rental to generate additional income for the building instead of using this unit as an on-site superintendent residence. In total, the building houses 27 adult residents, of which 24 are owners of the remaining 13 cooperative units. The co-op board is comprised of 5 members. The board has full voting power for all on-site decision-making, and votes must be majority (not unanimous) in order to enact new policies or implement new initiatives. Any resident in the building is welcome to suggest ideas. The board meets offsite at Treasurer's law office in Manhattan.

The building is comprised of young, well-educated professionals with above-average incomes. Resident explained that residents include movie producers, artists, and people who work for nonprofits. Of the twelve survey respondents, eleven were between the ages of 30-39 (with the remaining resident reporting their age as between 40-49). Only two respondents $(18 \%)$ reported an income below $\$ 100,000$, and one reported an annual income above $\$ 300,000$. The remaining respondents were evenly split, with 4 reporting annual incomes between $\$ 100,000$ and $\$ 199,000$ and 4 reporting annual incomes between $\$ 200,000$ and $\$ 299,000$. Gender was nearly even, with 7 male respondents and 5 female respondents. Most respondents (50\%) reported a household size of two people, but responses ranged 
between one and four residents. Anecdotally, it was reported in interviews that many owners currently have small children or often have children after purchasing in the building. All twelve respondents $(100 \%)$ reported their political orientation as somewhat or very liberal. All respondents reported a college education, with $42 \%$ holding a bachelor's degree and $58 \%$ holding a master's or other advanced degree. Residents were not asked to report race or ethnicity on the survey, but anecdotally it was reported in interviews that nearly all cooperative owners were white while the residents of the two rent-controlled units were black.

Of the interviewed individuals, Resident is a female in her late-30s who has lived in a 2-bedroom unit in the building with her husband and dog for approximately 3 years. In two of the three prior years of her tenure in the building she has served as both president and vice-president of the board. Treasurer is a male in his mid-60s who owns the most shares in the building and has been the board treasurer for nearly 3 decades. He was one of the original sponsors of the co-op conversion, and he is a lawyer.

\section{Results}

Findings from fieldwork can be summarized into three high-level outcomes. First, the building operates in a highly decentralized and transparent manner, with all residents familiar with their neighbors, board members, and building decision making; social cohesion is high. Second, the building has undertaken a significant amount of capital improvement to address energy efficiency. Third, one ad-hoc leader in the building has effectively shaped a narrative of cost-efficiency as the motivation for energy efficiency investments; as a result, residents do not report that the building is environmentally conscious. These findings will be outlined in turn below with supporting evidence from surveys and interviews.

\subsection{A Decentralized and Transparent Building}

Findings regarding the property and its overall operations indicate that the organizational structure of the building is highly decentralized, residents know each other well, and decision-making is transparent. There is good social cohesion in the building. These findings are well-supported by surveys and interviews, outlined below.

Tenure in the building is generally steady, and residents are not highly transient. Nine out of twelve respondents have lived in the building for 3 or more years, with 5 respondents reporting their tenure at 5 years or longer. Only two of the twelve respondents have lived in the building less than a year.

Most respondents reported a high amount of interaction with their neighbors. Seven respondents (58\%) reported daily interactions with other residents, and 3 reported interactions once or twice a week. Only 2 respondents reported interaction with other residents 1-2 times a month, and zero respondents reported that they never interact with other residents. See Figure 1. 


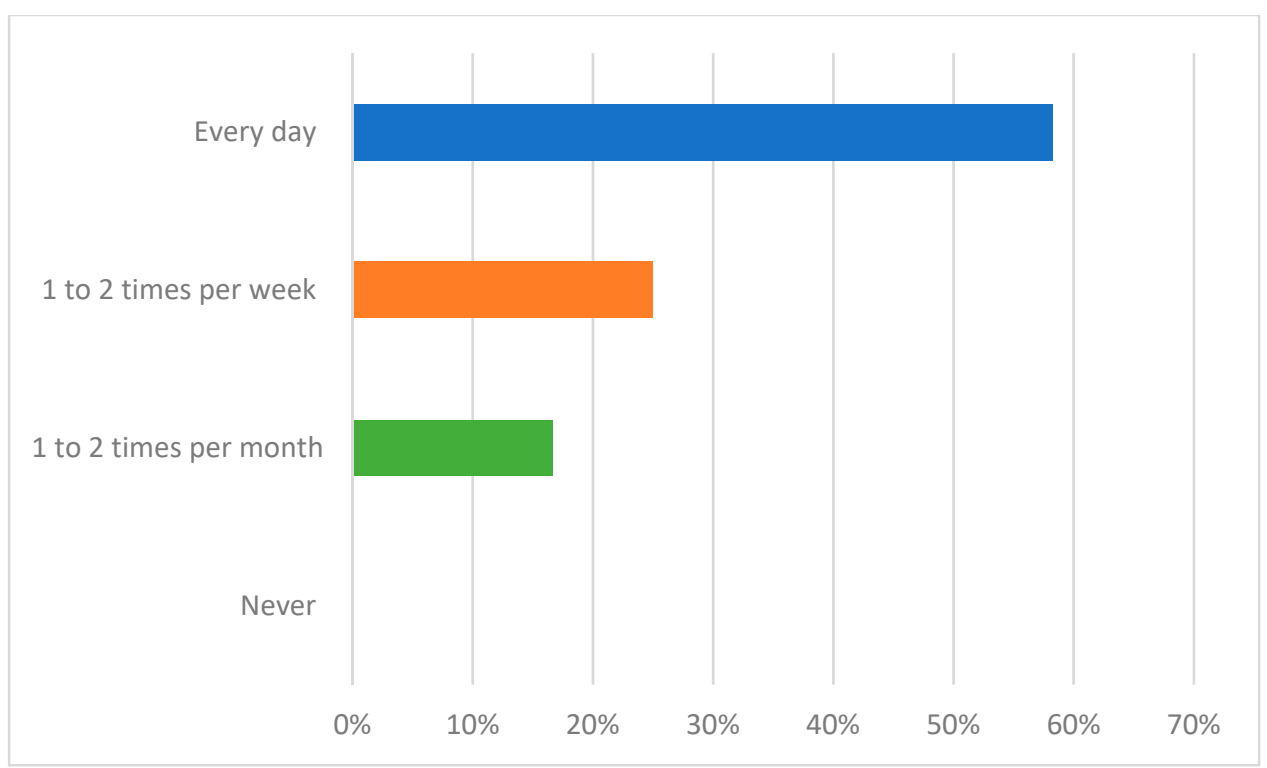

Figure 1. Resident interactions with other residents in the study building.

Residents answered a set of seven questions that attempted to assess their opinions about the strength of the relationships formed in the building and their sense of belonging and inclusion. Answer choices for all seven questions were organized along a Likert scale with five response categories ranging from strongly agree to strongly disagree. See Table 1 for a list of all seven questions and the survey results reported by residents on this section.

Table 1. Social connections and relationships among residents of the study building.

\begin{tabular}{|c|c|c|c|c|c|}
\hline & Strongly Agree & Agree & Neither Agree or Disagree & Disagree & Strongly Disagree \\
\hline $\begin{array}{l}\text { I have formed a strong } \\
\text { friendship with at least one } \\
\text { person in the building }\end{array}$ & $41.7 \%(5)$ & $41.7 \%(5)$ & $0.0 \%(0)$ & $8.3 \%(1)$ & $8.3 \%(1)$ \\
\hline $\begin{array}{l}\text { I have formed casual } \\
\text { acquaintances with many } \\
\text { people in the building }\end{array}$ & $58.3 \%(7)$ & $41.7 \%(5)$ & $0.0 \%(0)$ & $0.0 \%(0)$ & $0.0 \%(0)$ \\
\hline $\begin{array}{l}\text { My building encourages me } \\
\text { to get to know my } \\
\text { neighbors through social } \\
\text { activities, shared spaces, } \\
\text { projects in the building, and } \\
\text { other on-site activities }\end{array}$ & $33.3 \%(4)$ & $33.3 \%(4)$ & $8.3 \%(1)$ & $25.0 \%(3)$ & $0.0 \%(0)$ \\
\hline $\begin{array}{l}\text { I feel a sense of connection } \\
\text { and belonging in } \\
\text { my building }\end{array}$ & $50.0 \%(6)$ & $25.0 \%$ & $0.0 \%(0)$ & $16.7 \%(2)$ & $8.3 \%(1)$ \\
\hline $\begin{array}{l}\text { I am aware of discussions } \\
\text { that are made for/about my } \\
\text { building by the co-op board }\end{array}$ & $41.7 \%(5)$ & $33.3 \%(4)$ & $0.0 \%(0)$ & $0.0 \%(0)$ & $25.0 \%(3)$ \\
\hline $\begin{array}{l}\text { I am included in the } \\
\text { decision-making of } \\
\text { the building }\end{array}$ & $16.7 \%(2)$ & $16.7 \%(2)$ & $16.7 \%(2)$ & $25.0 \%(3)$ & $25.0 \%(3)$ \\
\hline $\begin{array}{l}\text { My opinion matters in the } \\
\text { decision-making of } \\
\text { the building }\end{array}$ & $16.7 \%(2)$ & $41.7 \%(5)$ & $16.7 \%(2)$ & $8.3 \%(1)$ & $16.7 \%(2)$ \\
\hline
\end{tabular}


The results indicate that nearly $83 \%$ of respondents (10 respondents out of 12 ) reported that they have formed at least one close friendship in the building, while all twelve respondents reported that they have formed casual friendships or acquaintances with many residents in the building. Two-thirds of residents (8 respondents) agreed or strongly agreed that the building helps facilitate getting to know neighbors. Three residents disagreed with this statement. Nine out of 12 respondents agreed or strongly agreed that they felt a sense of belonging in the building. Similarly, in interviews Resident reported a number of close friendships in the building, explaining that two other couples in the building have spare sets of her keys, and that they often do things together as couples. She also explained that the building has weekly Sunday backyard gatherings in warmer months where any resident who is available and wants to join can come hang out in the backyard with a bottle of wine.

The final three questions in this set asked respondents if they agreed or disagreed that they were aware of decisions made in the building, included in the decision-making in the building, and that their opinions about decisions mattered. Responses to these questions were more evenly dispersed across the strongly agree to strongly disagree spectrum.

When asked how important their social relationships in the building were relative to social relationships outside of the building, half of the respondents (6 occupants) reported that their social relationships in the building were just as important as those outside of the building. Half reported these relationships were less important. None reported that the relationships in the building were more important.

Of the twelve respondents, 5 had served on the board at some point during their tenure in the building, while 7 had not. All respondents reported knowing their board members either a little or very well. No respondents reported wanting less input in the decision-making of the building than they currently have. Seven respondents reported they are satisfied with their current amount of input in the building, and 5 reported they would like more input.

In Resident's follow-up interview about her time as board president and vice president, she explained that the monthly maintenance price every resident must pay-which supports functions like common areas, superintendent, and supplies-is based on number of shares owned. She pays approximately $\$ 700$ per month. Those with more shares (based on square footage) pay a higher monthly co-op fee. Common areas include the basement bike room, storage space, laundry room, backyard (which has lights and cameras), front yard (which is rarely used), and hallways. Laundry machines are reduced but not free, and money from those machines is added into the building's operating account, which is used to purchase light bulbs, gardening supplies, and other necessities. When asked who purchased those necessities she replied:

"Whoever. If you notice it, you can buy it. You just submit your receipt and get reimbursed. Or you can tell the super. He has an account at Home Depot for our building."

Entry into the building requires a full board packet with 6 months of financials and bank statements along with references. However, the board has not rejected anyone in the last 10 years.

\subsection{Energy and Environmental Findings}

Findings regarding energy and environmental initiatives in the building indicate that the property has elected to invest in a significant number of capital improvement projects to help the building operate more efficiently. These projects have also saved a significant amount of energy. However, most residents do not report that the building engages in energy efficiency initiatives. These findings will be explained below.

According to Resident and Treasurer, a number of capital improvements have been made that have greatly increased the energy efficiency of the building. The building replaced the boiler in 2000 to dual-fuel equipment and decided to switch to oil (from gas); they have subsequently switched back to gas due to lower prices. Windows in the building have been mostly all replaced and are highly insulated. Individual residents must opt to 
replace windows in their unit, but the building pays for one-third of the cost. Treasurer also explained that the building recently installed a more sophisticated "heat computer" to replace the older heat timers that only measured the outdoor temperature if it was below 55 degrees $\mathrm{F}$, which created steadily high indoor temperatures near 80 degrees with no more sophisticated way of controlling the heat system. Most residents complained often of being too hot. Resident said:

"We couldn't control the heat. All we could do was turn the radiators off. Now we have staggered sensors at opposite ends of the building. Our system is so old. We have all been so much happier."

Half of the respondents ( 6 respondents) reported that they try to conserve energy at home every day, and an additional 4 respondents (33\%) reported that they try to save energy at home 1-2 times a week. Only 1 respondent reported that they try to conserve energy at home 1-2 times a month, and only 1 respondent reported that they never try to conserve energy at home.

When asked about building-wide efforts to conserve energy and resources, only one individual responded that the building actively tries to encourage conservation of resources, and this individual reported that this is primarily done through informational methods (e.g., posting notices in lobby, sharing information on the Google portal). All other residents responded either that the building does not actively try to encourage conservation of resources, or that they did not know.

When asked if there was a "culture of conservation" in their building, answers were mixed. No respondents strongly agreed. Thirty-six percent of respondents (4 individuals) agreed, and another $36 \%$ felt neutral (neither agreed nor disagreed). The remaining three respondents either disagreed ( 2 individuals) or strongly disagreed (1 individual). Resident felt slightly differently. She explained:

"We've been taking small steps to make the building more energy efficient. I'd rank us like $a$ or a 7 on how important it is to conserve in the building. The building composts. We use it to fertilize the garden. Everyone puts their stuff in it. We buy green (cleaning products)."

Nearly all respondents (9 individuals, or 82\%) reported that they "care a little" about what others in the building thought about their recycling or consumption habits at home.

\subsection{A Culture of Cost-Efficiency}

As reported above, the building has undertaken a number of capital improvement projects that have had an impact on energy costs and consumption. Interestingly, residents of the building do not report that the building undertakes energy efficiency initiatives or actively tries to conserve resources. Treasurer has shaped this outcome through a strong narrative of cost-efficiency over environmental concern, which has been well-distributed among residents because of his role as a leader in the building.

Treasurer has had a number of years in which to establish this leadership role in the building. He explained his decades-long role in the property:

"Myself and three other people were the sponsors of the conversion to co-op. Of those 4, one died, and another walked away from his interest. This was in about 1990 when the real estate market was in really poor shape. Since he left, the management fell to me. And I've been involved in varying degrees since then. There were 3 owner-occupants when I got involved in the building. Five of the 16 apartments had been sold. And the owner occupants, with the exception of one person, were not active in the building. So, the management of it, since we owned 11 apartments, by default the management fell to me."

Thus, Treasurer has not only been board treasurer for decades, he was in many ways running the building in its early days as a cooperative. 
Additionally, as Resident recounts, Treasurer has always been the board treasurer; he must be voted into that role each year, but people always vote for him. His long-standing tenure on the board as the treasurer means that, to non-board members,

"He sets what are seemingly arbitrary rules. But people know that if he leaves it would be so much harder."

As treasurer, he pays the electricity bills for the common area spaces. In addition to Treasurer, one other long-standing resident ("Rosie") always sits on the board, and has lived in the building since the 1940s. It is often the case according to Resident that board decisions come down to Rosie and Treasurer "against the young people" on the board.

In addition, although most building residents are not highly transient, both interviewees reported a fairly high amount of turnover because many young families outgrow their apartments in the building after a few years of ownership. Resident explained:

"I think it's a very family-friendly building, all of the apartments in the back have 2 bedrooms, so people can start families here, but then they move out. If we had a kid, we couldn't be here very long."

Treasurer explained:

"The situation is that it's most people's first purchase, so you know, kids come along, kids get bigger, then they're looking for a bigger place. But, you know, it tends to be people of a similar outlook, and they're interested in the wellbeing of the building and keeping costs down. Hopefully there's some carryover (on the board) and you get more people like (Resident)."

This leadership role, established over decades and lasting for much longer than the tenure of other (younger, newer) homeowners in the building, has allowed Treasurer's narrative of cost efficiency to be well dispersed among residents. Interviews provided significant evidence of Treasurer's leaning towards saving money in the building. He repeatedly mentioned costs, savings, and prices.

Regarding the switch from gas to oil in 2000, Treasurer noted:

"This sounds a little bizarre," he explained, "but at the time it was a good decision. We've subsequently converted to duel fuel, and we've been running it on gas. The price of gas has dropped tremendously. The ability to switch fuels has been huge." He also explained that the building maintained a separate hot water heater, "but because of the boiler that was running anyway, we got almost free hot water in the winter."

In summer months, the building relies on the separate hot water heater. Regarding the installation of the new, more sophisticated heat computer, this change has had "monumental impacts" on both comfort and cost, according to Treasurer, bringing the average indoor temperature down to around 70 degrees, and has reduced heating costs by approximately a third.

When asked directly what the primary motivation behind these and other initiatives was, Treasurer said:

"The motivation was not environmental. It was to reduce costs and increase comfort. Some people may look at it from an environmental perspective. But that wasn't my goal."

Regarding common area electricity consumption over the years of his time as treasurer, Treasurer explained:

"Well, there hasn't really been any material change except the price has gone up. I haven't really seen any change in usage. At some point we replaced the light fixtures, and we tried to use more energy efficient lighting."

When asked if he agreed that owner-occupied properties, and cooperative buildings in particular, are likely to consume less energy, Treasurer said:

"Hmm. If that's true, it's that co-op people expect that they will pay for things. They recognize that they are paying for things. When people aren't paying for something they 
use more of it. Perhaps people in co-ops are more cost conscious. But, a properly run rental building will have a cost conscious landlord too. But I guess a co-op board would be more sensitive to things. You can have an increase in the maintenance charge when the heat is going up $10 \%$ or $15 \%$. A few years ago we had a fuel assessment. It got everybody's attention. It made everyone ask what are we doing about it."

\subsection{Interview Summary}

As a qualitative case study, the full quotes provided in the prior sections offer context and nuance, which are necessary insights into this specific case and the goal of this analysis. However, it is useful to see higher-level summary findings as well. The interviews were coded to assess language and narratives, and to connect overlaps between the interview subjects. Table 2, below, summarizes some of the key language and words, themes, and emphasis deemed important for this work. The supporting findings are organized by the three high-level areas described above (a decentralized and transparent building; energy and environmental findings; a culture of cost-efficiency).

Table 2. Summary interview findings organized by theme/finding area.

\begin{tabular}{|c|c|c|}
\hline Theme/Finding & Resident & Treasurer \\
\hline \multirow{3}{*}{ Decentralized \& Transparent Building } & $\begin{array}{l}\text { - Use of language such "we," and } \\
\text { "us" when describing building } \\
\text { decisions and activities }\end{array}$ & $\begin{array}{l}\text { - Clear understanding and } \\
\text { conveyance of board procedures } \\
\text { and decision making }\end{array}$ \\
\hline & $\begin{array}{l}\text { - Descriptions of frequent resident } \\
\text { social interactions }\end{array}$ & $\begin{array}{l}\text { - Mention of other residents by } \\
\text { first name }\end{array}$ \\
\hline & $\begin{array}{l}\text { - Clear understanding and } \\
\text { conveyance of board procedures } \\
\text { and decision making }\end{array}$ & $\begin{array}{l}\text { - Emphasis on building's small size } \\
\text { and small board }\end{array}$ \\
\hline \multirow{2}{*}{$\begin{array}{l}\text { Energy and } \mathrm{f} \\
\text { Environmental } \\
\text { Findings }\end{array}$} & $\begin{array}{l}\text { Descriptions of projects to increase } \\
\text { comfort level(s) (e.g., new windows, } \\
\text { better heat sensors) }\end{array}$ & $\begin{array}{l}\text { - Descriptions of major building-wide } \\
\text { infrastructure projects }\end{array}$ \\
\hline & $\begin{array}{l}\text { - Mention of "green" products } \\
\text { and materials }\end{array}$ & $\begin{array}{l}\text { - Emphasis on efficiency in discussing } \\
\text { all upgrades and projects }\end{array}$ \\
\hline \multirow{2}{*}{$\begin{array}{l}\text { Culture of Cost- } \\
\text { Efficiency (e.g., } \\
\text { Treasurer's leadership role in shaping } \\
\text { building's culture) }\end{array}$} & $\begin{array}{l}\text { - Frequent reference to Treasurer's } \\
\text { knowledge, information, and } \\
\text { history in building }\end{array}$ & $\begin{array}{l}\text { - Frequent use of active language in } \\
\text { first person, such as "I decided," "I } \\
\text { implemented," "I felt," and } \\
\text { "my goal" }\end{array}$ \\
\hline & $\begin{array}{l}\text { Emphasis on comfort level increase } \\
\text { as primary outcome of } \\
\text { projects / retrofits }\end{array}$ & $\begin{array}{l}\text { - Use of language such as "money," } \\
\text { "costs,," "cheaper," "paying for" }\end{array}$ \\
\hline
\end{tabular}

\section{Discussion}

The findings above indicate that the building has undertaken a significant amount of capital improvement to address energy efficiency. Despite these investments, residents overwhelmingly report that the building does little to conserve energy, and that there is not a culture of conservation in the building. These contradictory outcomes can be attributed in part to the leadership and influence of Treasurer, the board member with the longest tenure in the building; as board treasurer, this individual has encouraged and actively pursued energy efficiency investments, while also actively and vocally crafting a narrative and culture around cost efficiency within the building. It is this culture that informs both the perceived impetus behind the implementation of energy efficient capital improvements as well as the perceived lack of a conservation culture or active conservation efforts among 
residents in the building. This research argues that there are two primary reasons for the success of Treasurer's influence in crafting this narrative. They will be discussed below.

First, his long tenure has been highly influential for younger, newer, often first-time homebuyers in the building. As reported by Treasurer, the implementation of many energy efficiency initiatives over the years was not motivated by a concern for energy conservation, but by a concern for cost savings. From an economic and organizational perspective, this makes sense. Implementing capital improvements to save money over the long term in a cooperative is an efficient and rational decision given shared ownership. It highlights the lack of principal-agent issues in cooperatives. In addition, it points to the benefits of this type of ownership structure in reducing transaction costs for homeowners; since they are members of a collective, they do not have to access and analyze information, weigh competing alternatives, and make investment decisions for expensive capital improvements as a single owner of a single-family structure. Additionally, New York City is a special case given the ubiquitous presence of the cooperative building as a housing type. Since the city has many decades of experience in the legal structures of co-op ownership, cooperatives have an even deeper transaction cost advantage over other forms of homeownership, like condominiums [23]. Thus, although it would make for a compelling story if the building was motivated by environmental concern alone, for these reasons it makes sense that the decisions to implement energy efficient capital improvements were borne out of an efficient and economically rational self-interest. However, this building has the particular advantage of having the longest-standing board member, who brings with him knowledge of the evolving history of the property, also serving in the role of treasurer. This individual is able to understand and analyze financial information in an informed manner and with an historical perspective other residents may not have, so that the building can make smart decisions about evolving cost concerns and potential capital improvements over the long-term. Many residents rely on this individual's knowledge and expertise, giving legitimacy to his suggestions and ideas.

Second, the highly decentralized and transparent organizational structure of this building gave Treasurer an organizational advantage in influencing the "messaging" surrounding capital improvements. It is likely that all cooperative buildings are decentralized to some extent, given that board membership is comprised entirely of residents, but some larger cooperatives will have more hierarchical and centralized board structures with a number of residents who do not participate. In this case study building, however, with only 24 adult co-op owner residents and 13 owner-occupied units with a 5-person board (with voting on membership occurring annually), everyone in the building at any given time is likely to either be on the board, living with someone on the board, or friends with someone on the board. It is unlikely, given survey responses regarding how well individuals know the board members, how many friendships and casual acquaintances residents have, and how many individuals have served on the board themselves, that any individual in the building could have absolutely no knowledge of who is on the board, the decisions they make, or how they can become more involved. To most residents, the board structure is both transparent and closely linked to their daily lives, and they feel they have the ability to impact decisions. Residents are likely to feel a high level of perceived control—an individual's perception of the ability they have to take action or bring about change on issues that matter to them-regarding the operation and decision-making in the building $[26,28]$. It is argued here that, taken together, this means residents do not view themselves as outside of or separate from the decision-making process, but as part of the structure itself [4]. This creates an important level of visibility and influence for the leadership of Treasurer. He is not "separate" from the other residents, but a resident himself, well-connected and visible. $\mathrm{He}$ is able to interact with all residents, and all residents are likely to know him and his role within the building. This, too, has influenced the success of Treasurer's narrative in shaping perception and culture in the building.

The above points lead to a few recommendations for research and policy. First, this work highlights the importance of informal and ad-hoc leadership positions in influencing 
others in organizations. These roles need to be acknowledged as important, just as more formal managers and supervisors are in traditional organizations. In buildings, this means giving more weight to the role of individuals other than the building manager. Acknowledging the role these individuals play highlights the need to better understand the mechanisms they use to communicate with others, shape culture and norms, and influence organizational outcomes.

Second, the findings here highlight the ability of leaders to shape culture and perception. In the study building, Treasurer was able to craft a strong and compelling narrative of cost efficiency as motivation for undertaking a number of energy efficiency improvements. This highlights the important potential to leverage existing leadership roles in buildingssuch as that of Treasurer-in order to shift the organizational narrative to one that blends energy efficiency for cost as well as environmental reasons. The narrative as a tool has the potential to create a culture of energy efficiency and environmental conservation in buildings, and this could help make building-wide efforts to conserve energy more effective. What would the trickle-down effect of this narrative be on building residents and perhaps in individual households? This remains to be seen, but opens up an important area for future research, particularly as policymakers and others recognize the need to tackle energy use in the building stock in order to reach city, state, and national goals for reduction of $\mathrm{CO}_{2}$ emissions.

Finally, evidence presented here indicates that decentralization and strong leadership (usually a characteristic of a centralized organizational structure) can be complementary and synergistic, not contradictory. The high level of decentralization in the study building was a benefit to the leader's influence; in a different type of building, such as a rental, this is likely not the case [2]. However, it could be taken advantage of even further by capitalizing on the decentralized and transparent structure to encourage and motivate others to take leadership roles as well. Additional individuals could shape the culture of energy efficiency through new and different narratives. Thus, in instances where some organizational factors are already in place — such as a cooperative building with a high-level of decentralization-policies and programs should be considered that strengthen those existing characteristics while allowing for synergistic benefits with potentially contradictory elements. For instance, in buildings with very tightly controlled boards that exhibit a high level of centralization and solicit little input from other residents, perhaps term limits on board membership would be effective, or requiring a mandatory year of service from all residents. Similarly, in buildings such as the study building presented here, where one individual fills a long-term board role (e.g., treasurer), perhaps mandatory rotation of roles could become a cooperative board policy.

\section{Conclusions}

This research presented interesting and important findings about the culture surrounding energy conservation in a small, older cooperative building in Prospect Heights, Brooklyn. This building operated in a decentralized and transparent manner and has implemented a number of energy efficiency measures. However, most residents did not report active engagement with building-wide energy efficiency. This outcome was attributable to the leadership of one long-standing individual who serves as board treasurer and has shaped the culture for action in the building over prior decades as one of cost efficiency over environmental concern. In this particular building, the narrative was so successful because of the organizational structure of the cooperative, and because of this individual's role as a legitimate leader in the building.

Low $[20,21,44]$ provides one of the most comprehensive bodies of qualitative and ethnographic work on cooperative buildings in New York City, but no work, to the knowledge of the author, has attempted to meld this understanding of the social and cultural aspects of cooperative buildings with evidence regarding energy consumption, opening up a vast potential for future work. 
One avenue would be to replicate a study such as the one presented here in a cooperative building that is larger. This would provide the opportunity to better understand and distinguish between those factors presented here that have occurred because of the cooperative's organizational structure itself or because of the building's small size. Would an informal leader's narrative be so well disseminated in a property with many more residents? How would that message spread throughout a large building, and what tools would leaders and others need in order to be effective? This remains to be seen. It would also allow for a larger sample size, which is a limitation in this research.

Similarly, it would be useful to replicate this study in a building where full-building energy data is available. Although there is value to the qualitative data presented here and the in-depth look at the perceptions of residents, it would be helpful to link this subjective and self-reported data to actual observed energy use.

Finally, it would be interesting to further study a cooperative building that was designed as a green building or has been retrofitted to now operate as a green building. The organizational culture is likely to be very different in a green building, as the motivation behind energy efficiency will surely include at least a moderate amount of environmental concern, and it would be helpful to observe how this impacts outcomes.

Funding: This research received no external funding.

Institutional Review Board Statement: This study was conducted according to the guidelines of the Declaration of Helsinki, and approved by the Institutional Review Board of Rutgers, The State University of New Jersey (protocol 14-470M approved 3 February2015).

Informed Consent Statement: Informed consent was obtained from all subjects involved in the study.

Data Availability Statement: The data presented in this study are available on request from the corresponding author. The data are not publicly available due to participant privacy restrictions.

Acknowledgments: Special thanks to the residents and board members of the anonymous case-study building that provided the site for this research.

Conflicts of Interest: The author declares no conflict of interest.

\section{Appendix A. Survey Instrument}

To begin the survey now, click here.

(INFORMED CONSENT WILL APPEAR ON NEXT PAGE-RESPONDENT MUST CLICK “YES” FOR ELECTRONIC ACKNOWLEDGMENT IN ORDER TO PROCEED TO THE SURVEY.

(MODULE PART A: FOR ALL RESPONDENTS)

QA1: How long have you lived in your current building?

1. Less than one year

2. 1-2 years

3. 3-4 years

4. 5 years or more

QA2: How often would you say you interact with other residents in your building?

1. Never

2. Sometimes

3. Often

4. Every day

QA3: Do you agree or disagree that you have been able to form social relationships with residents and neighbors in your building.

1. Strongly agree

2. Agree

3. Neither agree or disagree 


\section{Disagree \\ 5. Strongly disagree}

QA4: Do you agree or disagree that your building encourages you to get to know your neighbors through social activities, shared spaces, projects in and around the building, and other on-site activities?

1. Strongly agree

2. Agree

3. Neither agree or disagree

4. Disagree

5. Strongly disagree

QA5: Thinking about the building overall, would you agree or disagree that you feel a sense of connection and belonging to your building?

1. Strongly agree

2. Agree

3. Neither agree or disagree

4. Disagree

5. Strongly disagree

QA6: Do you currently or have you previously served on the board of your building at some point during your time as a resident?

1. Yes

2. No

(If QA6 = 1)

QA7: What position did you or do you currently hold on your board?

QA8: How well do you feel you know the board members in your building:

1. I don't know them at all

2. I know them a little

3. I know them very well

QA9: Do you agree or disagree that you are aware of decisions that are made for/about your building by the co-op board:

1. Strongly agree (I am entirely aware of all decisions made by the board)

2. Agree

3. Neither agree or disagree

4. Disagree

5. Strongly disagree (I am not at all aware of decisions that are made by the board)

QA10: Do you agree or disagree that you are included in the decision-making for your building (even if you are not on the board currently):

1. Strongly agree

2. Agree

3. Neither agree or disagree

4. Disagree

5. Strongly disagree

QA11: Do you agree or disagree that your opinion matters in the decision-making of the building:

1. Strongly agree (my opinion matters very much and is taken into account when the building makes decisions)

2. Agree

3. Neither agree or disagree

4. Disagree 
5. Strongly disagree (my opinion does not matter at all and plays no role in any decisionmaking in the building)

QA12: Would you like to have more input, less input, or about the same amount of input as you do currently in the decision-making of the building?

1. I would like more input

2. I would like less input

3. I am satisfied with my current amount of input

(END OF PART A: Respondent hits next button)

(MODULE PART B: ENERGY and CONSERVATION)

This next set of questions asks you about your opinions on energy efficiency and conservation in your apartment and building.

QB1: How often would you say you make a conscious effort to save energy at home?

1. Every day

2. A few times a week

3. Once a week

4. Once a month

5. Rarely/Never

(IF QB1 $=1,2$, OR 3)

QB2: What is the most important reason why you try to save energy at home? Select one.

1. To save money on my monthly electric bill

2. To set a good example for my family, children, or other people I live with

3. To avoid being wasteful

4. To do my part to help lessen energy consumption in my building

5. Other (please specify)

QB3: Does your building (the board, the super or manager, other residents) actively try to encourage conservation of resources like water and electricity?

1. Yes

2. No

3. Don't know

(IF QB3 = 1) QB4: How does the building go about encouraging conservation?

1. Sharing information (emails, flyers up in mail room, etc.)

2. Training programs

3. Special events for residents (composting, efficient light bulb giveaways)

4. Financial incentives or penalty (a rebate or a common area electricity/water charge that all residents must pay)

5. Other (please describe)

QB5: Would you agree or disagree that there is a "culture" of conservation in your building?

1. Strongly agree

2. Agree

3. Neither agree nor disagree

4. Disagree

5. Strongly disagree

QB6: How much would you say you care what other people in the building think about your recycling habits, or how you use electricity or other resources at home?

1. I do not care at all

2. I care a little

3. I care a lot

(END OF PART B-Respondent hits next button)

(MODULE PART C: DEMOGRAPHICS) 
This last set of questions asks for some information about you and your household. QC1: What is your age?
1. $18-25$
2. $26-30$
3. $30-39$
4. $40-49$
5. $50-59$
6. $60-69$
7. Over 70

QC2: Which of the following best describes your political affiliation?
1. Very liberal
2. Somewhat liberal
3. Moderate
4. Somewhat conservative
5. Very conservative

QC3: What is the highest level of education you have completed?
1. High school
2. Some college
3. Associates degree
4. Bachelors degree
5. Graduate school-Masters degree, MBA, JD, PhD or MD

QC4: What is your approximate household income?
1. Under $\$ 25,000 /$ year
2. $\$ 25,000-\$ 49,999 /$ year
3. $\$ 50,000-\$ 74,999 /$ year
4. $\$ 75,000-\$ 99,999 /$ year
5. $\$ 100,000-\$ 149,999 /$ year
6. $\$ 150,000-\$ 199,999 /$ year
7. Over $\$ 200,000 /$ year

QC5: Are you-
1. Male
2. Female

QC6: How many total people live in your home (including yourself)?
1. 1 person
2. 2 people
3. 3 people
4. 4 people
5. 5 or more people

QC7: What is your apartment type?
1. Studio
2. 1 bedroom
3. 2 bedroom
4. 3 bedroom
5. Other (please describe)

(END) You have reached the end of the survey. Thank you for your participation! Click here to submit your survey. 


\section{References}

1. Prindle, W.; Finlinson, S. How organizations can drive behavior-based energy efficiency. In Energy, Sustainability and the Environment; Technology, Incentives and Behavior; Sioshansi, F.P., Ed.; Butterworth-Heinemann: Burlington, NJ, USA, 2011; pp. 305-335.

2. Hewitt, E. Organizational characteristics in residential rental buildings: Exploring the role of centralization in energy outcomes. In Handbook of Sustainability and Social Science Research; Springer International Publishing: Cham, Switzerland, 2017.

3. Schelly, C.; Cross, J.E.; Franzen, W.S.; Hall, P.; Reeve, S. Reducing Energy Consumption and Creating a Conservation Culture in Organizations: A Case Study of One Public School District. Environ. Behav. 2011, 43, 316-343. [CrossRef]

4. Senge, P.M. The Fifth Discipline: The Art \& Practice of The Learning Organization, Revised\&Updated ed.; Doubleday: New York, NY, USA, 2010.

5. de Teixeira, E.O.; Werther, W.B. Resilience: Continuous renewal of competitive advantages. Bus. Horiz. 2013, 56, 333-342. [CrossRef]

6. George, J.M. Understanding and Managing Organizational Behavior, 6th ed.; Prentice Hall: Boston, MA, USA, 2012.

7. Mintzberg, H. Structure in Fives: Designing Effective Organizations, 1st ed.; Prentice Hall: Englewood Cliffs, NJ, USA, 1992.

8. Axon, C.J.; Bright, S.J.; Dixon, T.J.; Janda, K.B.; Kolokotroni, M. Building communities: Reducing energy use in tenanted commercial property. Build. Res. Inf. 2012, 40,461-472. [CrossRef]

9. Janda, K.B. Building communities and social potential: Between and beyond organizations and individuals in commercial properties. Energy Policy 2014, 67, 48-55. [CrossRef]

10. Hillier, B. Space Is the Machine: A Configurational Theory of Architecture; Cambridge University Press: Cambridge, UK, 1998.

11. Hall, E.T. The Hidden Dimension; Anchor: New York, NY, USA, 1990.

12. Deline, M.B. Energizing organizational research: Advancing the energy field with group concepts and theories. Energy Res. Soc. Sci. 2015, 8, 207-221. [CrossRef]

13. Vinkhuyzen, O.M.; Karlsson-Vinkhuyzen, S.I. The role of moral leadership for sustainable production and consumption. J. Clean. Prod. 2014, 63, 102-113. [CrossRef]

14. Wesselink, R.; Blok, V.; Ringersma, J. Pro-environmental behaviour in the workplace and the role of managers and organisation. J. Clean. Prod. 2017, 168, 1679-1687. [CrossRef]

15. Birkland, T.A. An Introduction to the Policy Process: Theories, Concepts, and Models of Public Policy Making, 4th ed.; Routledge: New York, NY, USA, 2016.

16. Hermwille, L. The role of narratives in socio-technical transitions_Fukushima and the energy regimes of Japan, Germany, and the United Kingdom. Energy Res. Soc. Sci. 2016, 11, 237-246. [CrossRef]

17. Havermans, L.A.; Keegan, A.; den Hartog, D.N. Choosing your words carefully: Leaders' narratives of complex emergent problem resolution. Int. J. Proj. Manag. 2015, 33, 973-984. [CrossRef]

18. Thurlow, A.; Mills, J.H. Telling tales out of school: Sensemaking and narratives of legitimacy in an organizational change process. Scand. J. Manag. 2015, 31, 246-254. [CrossRef]

19. Pinnington, A.; Alshamsi, A.; Karatas-Ozkan, M.; Nicolopoulou, K.; Ozbilgin, M.; Tatli, A.; Vassilopoulou, J. Early Organizational Diffusion of Contemporary Policies: Narratives of Sustainability and Talent Management. Procedia Soc. Behav. Sci. 2015, 213, 807-811. [CrossRef]

20. Low, S. A multi-disciplinary framework for the study of private housing schemes: Integrating anthropological, psychological and political levels of theory and analysis. GeoJournal 2012, 77, 185-201. [CrossRef]

21. Low, S.; Donovan, G.T.; Gieseking, J. Shoestring democracy: Gated condominiums and market-rate cooperatives in new york. J. Urban Aff. 2012, 34, 279-296. [CrossRef]

22. Rosen, G.; Walks, A. Rising cities: Condominium development and the private transformation of the metropolis. Geoforum 2013, 49, 160-172. [CrossRef]

23. Hansmann, H. Condominium and Cooperative Housing: Transactional Efficiency, Tax Subsidies, and Tenure Choice. J. Leg. Stud. 1991, 20, 25-71. [CrossRef]

24. Hewitt, E.L.; Andrews, C.J.; Senick, J.A.; Wener, R.E.; Krogmann, U.; Allacci, M.S. Distinguishing between green building occupants' reasoned and unplanned behaviours. Build. Res. Inf. 2016, 44, 119-134. [CrossRef]

25. Khansari, N.; Hewitt, E. Incorporating an agent-based decision tool to better understand occupant pathways to GHG reductions in NYC buildings. Cities 2020, 97, 102503. [CrossRef]

26. Ajzen, I. Attitudes, Personality and Behavior, 2nd ed.; Open University Press: London, UK, 2005.

27. Fishbein, M.; Ajzen, I. Belief, Attitude, Intention and Behavior: An Introduction to Theory and Research; Addison-Wesley Pub (Sd): Boston, MA, USA, 1975.

28. Fishbein, M.; Ajzen, I. Predicting and Changing Behavior: The Reasoned Action Approach, 1st ed.; Psychology Press: East Sussex, UK, 2009.

29. Kleindorfer, P.R.; Kunreuther, H.G.; Schoemaker, P.J.H. Decision Sciences: An Integrative Perspective; Cambridge University Press: Cambridge, UK, 1993.

30. Stern, P.C. New Environmental Theories: Toward a Coherent Theory of Environmentally Significant Behavior. J. Soc. Issues 2000, 56, 407-424. [CrossRef]

31. Allcott, H. Social norms and energy conservation. J. Public Econ. 2011, 95, 1082-1095. [CrossRef] 
32. OPower. OPower Results. Available online: http:/ / opower.com/results (accessed on 1 November 2014).

33. Dupré, M.; Meineri, S. Increasing recycling through displaying feedback and social comparative feedback. J. Environ. Psychol. 2016, 48, 101-107. [CrossRef]

34. van Horen, F.; van der Wal, A.; Grinstein, A. Green, greener, greenest: Can competition increase sustainable behavior? J. Environ Psychol. 2018, 59, 16-25. [CrossRef]

35. Rubin, A.; Babbie, E.R. Essential Research Methods for Social Work, 2nd ed.; Brooks/Cole: Belmont, CA, USA, 2010.

36. Marshall, C.; Rossman, G.B. Designing Qualitative Research, 4th ed.; Sage Publications: Thousands Oaks, CA, USA, 2006.

37. Corbin, J.M.; Strauss, A.L. Basics of Qualitative Research: Techniques and Procedures for Developing Grounded Theory, 3rd ed.; Sage Publications, Inc.: Los Angeles, CA, USA, 2008.

38. Groves, R.M. (Ed.) Survey Methodology, 2nd ed.; Wiley: Hoboken, NJ, USA, 2009.

39. Stern, P. Changing Behavior in Households and Communities: What Have We Learned? In New Tools for Environmental Protection: Education, Information, and Voluntary Measures; National Academies Press: Washington, DC, USA, 2002; pp. 201-212.

40. Schwartz, S.H. Are There Universal Aspects in the Structure and Contents of Human Values? J. Soc. Issues 1994, 50, 19-45. [CrossRef]

41. Cordano, M.; Welcomer, S.; Scherer, R.F.; Pradenas, L.; Parada, V. A Cross-Cultural Assessment of Three Theories of ProEnvironmental Behavior: A Comparison Between Business Students of Chile and the United States. Environ. Behav. 2011, 43, 634-657. [CrossRef]

42. Steg, L.; Dreijerink, L.; Abrahamse, W. Factors influencing the acceptability of energy policies: A test of VBN theory. J. Environ. Psychol. 2005, 25, 415-425. [CrossRef]

43. Rubin, H.J.; Rubin, I. Qualitative Interviewing: The Art of Hearing Data, 2nd ed.; Sage Publications: Thousand Oaks, CA, USA, 2005.

44. Low, S.M. The Edge and the Center: Gated Communities and the Discourse of Urban Fear. Am. Anthropol. 2001, 103, 45-58. [CrossRef] 